\title{
LMA Extubation in Pediatric Patients: A Comparison of Inflated and Deflated LMA Cuff Methods
}

\begin{abstract}
Mahin Seyedhejazi ${ }^{1}$, Behzad Aliakbari Sharabiani ${ }^{*}{ }^{*}$, Hamid Ahmadpour ${ }^{1}$, Daryoush Sheikhzadeh ${ }^{1}$, Marjan
\end{abstract} Dehdilani $^{1}$

1. Department of Anesthesiology, Tabriz University of Medical Sciences, Tabriz, Iran

\begin{abstract}
:
Background and Objectives: Extubating LMA (Laryngeal mask airway) can be performed either with inflated or deflated cuff. In this study the effects and complications of these two methods were compared in children.

Materials and Methods: In a clinical trial, 180 patients under 11 years old with ASA I/II who were scheduled for elective surgeries for less than one hour with no need for muscle relaxation were randomly divided into two groups. In group D, LMAs were extubated after oral cavity suctioning and cuff deflation. In group I, LMAs were extubated without suctioning and deflating the cuffs.

Results: In group I after removing the LMA, mean heart rate significantly increased, mean diastolic blood pressure significantly increased, and mean arterial blood saturation significantly decreased. In Group D, none of these changes occurred. Despite a higher incidence of complications in the group I, difference was not significant.

Conclusions: LMA removal with inflated cuff increases hemodynamic changes and decreases the arterial blood saturation. Hence, when hemodynamic stability and saturation of arterial blood is particularly important for us, extubating the LMA with deflated cuff is recommended.

Keywords: LMA; Complication; Inflated; Deflated
\end{abstract}

\section{Introduction:}

Airway management has always been of great importance for physicians (1). Laryngeal mask airway (LMA) is considered as a standard and acceptable device for supporting the airway in both adults and children (2). However, children have different requirements due to numerous factors like anatomical differences (3). Various methods have been introduced for LMA insertion (4); in addition, numerous methods have been introduced to decrease the complications associated with the LMA administration (5-9).

Despite the proven effectiveness of the

\section{Corresponding author:}

Behzad Aliakbari Sharabiani

Department of Anesthesiology, Tabriz University of Medical Sciences, Tabriz, Iran

E-mail: behzadaliakbarisharabiani@yahoo.com Tel: +989143075177

Received: 15-10-2013, Accepted: 16-11-2013, Published:

02-01-2014 DOI: 10.7575/aiac.abcmed.14.02.02.07 
LMA, there are some limitations. The biggest concern in its use is the probability of insufficient volume to fill in the LMA cuff which can be the result of air leakage (10). Using the LMA has many advantages but also is associated with functional limitations. Use of LMA requires careful insertion and removal. It has been mentioned in many resources that the laryngeal mask should be removed if the patient is fully awake to prevent the possible complications that may occur $(11,12)$. In other literatures, due to differences in physiology between adults and children such as children do not respond well to call, and the judge for the depth of anesthesia in children is difficult, its recommended to extubate LMA in anesthetic state in children (12-14).

Laryngeal mask removal while the children are in anesthetic state is considered in many studies that reduce many of the symptoms such as cough, increased heart rate, increased salivation and hypoxia (14); this however could be associated with the risk of airway obstruction (15).

To the best of our knowledge, no studies have been performed on the impact of the removal of the LMA with inflated or deflated cuff on patients' hemodynamic. This study was based on the comparison of LMA removal in deep anesthesia for children in two modes of inflated and deflated cuff.

\section{Methods and materials:}

In a controlled clinical trial performed in Tabriz Children's Hospital operating room, 180 children under 11 years old with ASA physical status of I or II and scheduled for elective surgery (less than an hour) without need to relaxant were randomly (Randomly Permuted Blocks) divided into two groups. We used online software available on the site URL: http://www.Stat.ubc.ca/Nrolin/statsssize/b2.ht $\mathrm{ml}$ to divide samples into two groups.
To determine the sample size of this study, we used the results of previous studies, considering that complications of LMA removal with full cuff was 10 . With $\alpha=0.05, d=0.2$, power $=80 \%$ and $p=0.1$, a sample size of 180 was estimated. Exclusion criteria were as follows: patients with potential difficult airway, risk of aspiration, and the obese patients $(30<\mathrm{BMI})$. Patients were divided into two groups: Group D (LMA removed deflated after suctioning around LMA and oral cavity) and Group I (LMA removal inflated and without suction).

Premedication was performed using Midazolam $0.03 \mathrm{mg} / \mathrm{kg}$ and fentanyl $1 \mu \mathrm{g} / \mathrm{kg}(10$ minutes before entering the operating room). Anesthesia induction was performed using lidocaine $1 \mathrm{mg} / \mathrm{kg}$ and propofol $2.5-3 \mathrm{mg} / \mathrm{kg}$. LMA size was selected based on the patient weight (size 1 for less than $5 \mathrm{~kg}$, size 1.5 for 5 $10 \mathrm{~kg}$, size 2 for $10-20 \mathrm{~kg}$ and size 2.5 for 20 $30 \mathrm{~kg})$. Anesthesia maintenance was performed using isoflurane $1.5-2 \%, \mathrm{~N}_{2} \mathrm{O} 1.5 \mathrm{lit} / \mathrm{min}$ and $\mathrm{O}_{2}$ $1.5 \mathrm{lit} / \mathrm{min}$. LMA extubation was performed in deep anesthesia status in both groups after anesthetic gases were discontinued. At the end of surgery in group $D$ after oral suction and deflation, LMA was removed. In Group I after the surgery, LMA (no deflation and no suction) were excluded. Incidence of complications such as cough, laryngospasm, limb movement during and after LMA removal was recorded. Changes in systolic blood pressure, diastolic blood pressure, heart rate and oxygen saturation were recorded before LMA insertion and before and after LMA removal.

Informed written consent (with full explanation of how to do to the parents) was obtained. This study is registered in IRCT (the Clinical Trial site) with Code 6N092540412011. All data were analyzed with statistical software SPSS version 16, using descriptive statistics (frequency, percentage, mean and standard deviation) and to compare qualitative variables 
chi square (and in the case of Fisher's exact test) and for quantitative variables the Independent $t$ test were used. To analyze the trends of variations in quantitative variables in two study groups, we used repeated measure of ANOVA. $P$ value of less than 0.05 was considered statistically significant.

\section{Results:}

180 patients were evaluated during the LMA removal in the two groups with inflated cuff $(n=90)$ and deflated cuff $(n=90)$. Table 1 shows the comparison of the baseline variables between the two groups. Four parameters including mean heart rate (HR), mean systolic blood pressure (SBP), mean diastolic blood pressure (DBP), mean arterial blood saturation after LMA insertion were compared in both groups and the results are given in Table 2 . As is noted the status of all parameters are similar in two groups after LMA insertion $(P>0.01)$. Comparison of hemodynamics between two groups before LMA removal has been shown in Table 3. As can be seen, the status of parameters in both groups at the stages immediately before LMA removal was similar and statistically insignificant. The mean of the four parameters after LMA removal period in two groups were compared immediately before LMA removal. Obtained data are shown in Table 4. As can be seen in the mean HR, DBP, and arterial oxygen saturation in Group $D$ are significantly different at two stages $(P<0.01)$. Despite the higher incidence of complications in the group I, using Fischer's exact test revealed that the difference was not statistically significant $(P=0.11)$. Figure 1 shows the prevalence of complications in two groups.

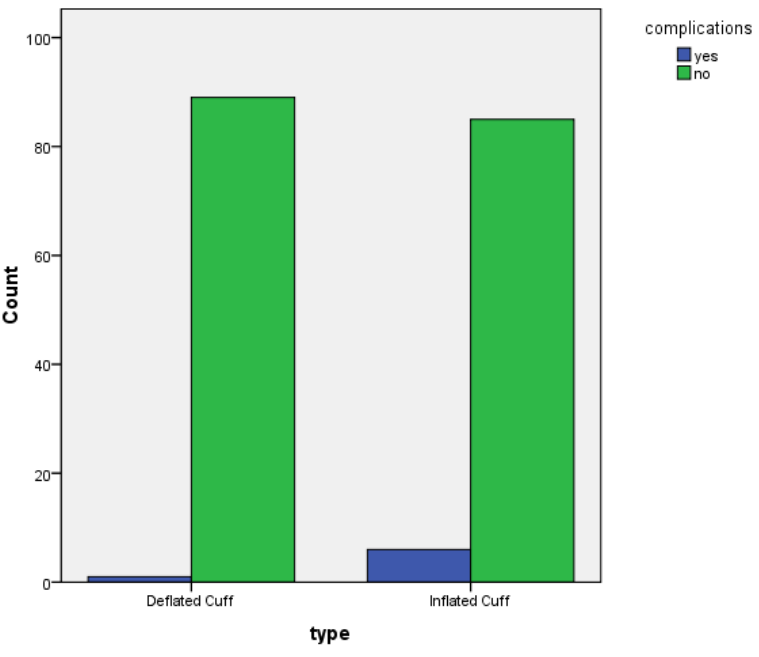

Figure 1: The prevalence of complications between the two groups

\section{Discussion:}

LMA provide a secure airway during general anesthesia without complications or need for muscle relaxants and therefore may be considered a viable alternative to the endotracheal tube (16). Laryngeal mask placement in children is not always easy, and several techniques described have been studied to improve the success rate of placing. It is very important that some of the built-in methods fail, and are associated with numerous attempts, adverse respiratory events and trauma in children (17).

In our study, variations in heart rate, systolic and diastolic blood pressure and arterial oxygen saturation were almost in the same trends in both groups before LMA removal. After removal of the LMA in the group I compared to group D, heart rate was significantly increased, DBP significantly increased and mean oxygen saturation decreased significantly. SBP was significantly increased after removing the LMA in both groups. 
variable Group D (Deflated) Group I (Inflated) P value

\begin{tabular}{lcccc}
\hline \multirow{2}{*}{ Age (year) } & $6.75 \pm 0.85$ & $4.76 \pm 0.98$ & 0.13 \\
\cline { 1 - 4 } gender & male & 87.7 & 86.8 & \multirow{2}{*}{0.9} \\
\cline { 2 - 4 } & female & 12.3 & 13.2 & \\
\hline Weight $(\mathrm{kg})$ & $17.10 \pm 7.87$ & $15.94 \pm 2.07$ & 0.68 \\
\hline Mean SBP $(\mathrm{mmHg})$ & $99.85 \pm 16.16$ & $96.85 \pm 16.92$ & 0.820 \\
\hline Mean DBP $(\mathrm{mmHg})$ & $53.32 \pm 14.97$ & $51.78 \pm 15.19$ & 0.744 \\
\hline Mean HR (Beat/min) & $122.77 \pm 26.27$ & $123.80 \pm 25.33$ & 0.282 \\
\hline
\end{tabular}

Table 1. Baseline data in two groups before anesthesia induction SBP: systolic blood pressure; DBP: Diastolic blood pressure; HR: heart rate

\begin{tabular}{lccc}
\hline variable & Group D (Deflated) & Group I (Inflated) & P value \\
\hline Mean HR (Beat/min) & $135.57 \pm 26.27$ & $123.80 \pm 25.33$ & 0.276 \\
\hline Mean SBP $(\mathrm{mmHg})$ & $88.65 \pm 13.83$ & $85.71 \pm 14.91$ & 0.203 \\
\hline Mean DBP $(\mathrm{mmHg})$ & $45.13 \pm 15.55$ & $42.59 \pm 12.69$ & 0.083 \\
\hline Mean SpO $(\%)$ & $99.5 \pm 0.67$ & $99.6 \pm 0.61$ & 0.083 \\
\hline
\end{tabular}

Table 2. Comparison of hemodynamics between two groups after LMA insertion

SBP: systolic blood pressure; DBP: Diastolic blood pressure; HR: heart rate;

$\mathrm{SpO}_{2}$ : Arterial oxygen saturation

Hemodynamic changes following LMA respiratory complications following LMA removal in group I were more significant than removal in inflated position. Despite the higher group D and arterial oxygen desaturation incidence of complications in group I, the occurred more often during LMA removal in difference was statistically insignificant. O'Brien group I which could have been due to et al.

\begin{tabular}{lccc}
\hline variable & Group D (Deflated) & Group I (Inflated) & P value \\
\hline Mean HR (Beat/min) & $123.92 \pm 22.78$ & $123.71 \pm 22.40$ & 0.948 \\
\hline Mean SBP $(\mathrm{mmHg})$ & $86.10 \pm 13.50$ & $83.30 \pm 12.89$ & 0.171 \\
\hline Mean DBP $(\mathrm{mmHg})$ & $39.87 \pm 11.18$ & $37.72 \pm 11.46$ & 0.223 \\
\hline Mean $\mathrm{SpO}_{2}(\%)$ & $99.5 \pm 0.67$ & $99.6 \pm 0.61$ & 0.083
\end{tabular}

Table 3. Comparison of hemodynamics between two groups before LMA removal

SBP: systolic blood pressure; DBP: Diastolic blood pressure; HR: heart rate;

$\mathrm{SpO}_{2}$ : Arterial oxygen saturation 


\begin{tabular}{lcccccc}
\hline variable & \multicolumn{2}{c}{ Group D (Deflated) } & \multicolumn{3}{c}{ Group I (Inflated) } & \\
\cline { 2 - 7 } & $\begin{array}{c}\text { Before } \\
\text { LMA } \\
\text { removal }\end{array}$ & $\begin{array}{c}\text { After LMA } \\
\text { removal }\end{array}$ & P-value & $\begin{array}{c}\text { Before LMA } \\
\text { removal }\end{array}$ & $\begin{array}{c}\text { After LMA } \\
\text { removal }\end{array}$ & P-value \\
\hline $\begin{array}{l}\text { Mean HR } \\
\text { (Beat/min) }\end{array}$ & $\begin{array}{r}123.92 \pm 22.7 \\
8\end{array}$ & $\begin{array}{r}125.40 \pm 26.5 \\
0\end{array}$ & 0.178 & $123.71 \pm 22.4$ & $128.07 \pm 23.9$ & $<0.001$ \\
\hline $\begin{array}{l}\text { Mean SB } \\
\text { (mmHg) }\end{array}$ & $86.10 \pm 13.50$ & $89.84 \pm 16.06$ & $<0.001$ & $83.30 \pm 12.89$ & $85.70 \pm 15.29$ & $<0.001$ \\
\hline $\begin{array}{l}\text { Mean DBP } \\
\text { (mmHg) }\end{array}$ & $39.87 \pm 11.18$ & $42.10 \pm 15.04$ & 0.023 & $37.72 \pm 11.49$ & $40.38 \pm 12.15$ & $<0.001$ \\
\hline $\begin{array}{l}\text { Mean SpO } \\
\text { (\%) }\end{array}$ & $99.5 \pm 0.67$ & $99.5 \pm 0.68$ & 0.576 & $99.6 \pm 0.61$ & $85.70 \pm 15.29$ & $<0.001$ \\
\hline
\end{tabular}

Table 4. Comparison of hemodynamics between two groups before and after LMA removal SBP: systolic blood pressure; DBP: Diastolic blood pressure; HR: heart rate; $\mathrm{SpO}_{2}$ : Arterial oxygen saturation

also reported similar respiratory complications in both their study groups (18). Unlike the findings of our study, Howard et al. indicated that rate of bleeding and cough in cases where the LMA removal performed with empty cuff was substantially less than the group with full cuff (19).

\section{Conclusion:}

Overall, it could be concluded that both LMA extubation methods in inflated and deflated cuff situation could be used safely in pediatric patients. However, LMA removal with inflated cuff increases hemodynamic changes and decreases the arterial blood saturation. Hence, when hemodynamic stability and saturation of arterial blood is particularly important for us, extubating the LMA with deflated cuff is recommended.

\section{Conflicts of interest}

The authors declare that they have no conflict of interest.

\section{References}

1.Golzari SE, Khan ZH, Ghabili K, Hosseinzadeh H, Soleimanpour H, Azarfarin R, Mahmoodpoor A, Aslanabadi S, Ansarin K. Contributions of medieval Islamic physicians to the history of tracheostomy. Anesth Analg. 2013;116(5):1123-32. doi: 10.1213/ANE.0b013e3182884313.

2.Seyedhejazi M, Eydi M, Ghojazadeh M, Nejati A, Ghabili K, Golzari SE, Iranpour A. Propofol for laryngeal mask airway insertion in children: Effect of two different doses. Saudi Journal of Anaesthesia 2013; 7(3):266-269.

3.Azarfarin R, Seyedhejazi M, Golzari SE, Bilehjani E, Ghabili K, Alizadehasl A. Do pediatric patients undergoing cardiac surgeries require larger-size cuffed endotracheal tubes? A prospective study. Paediatr Anaesth 2013; 23:228-32.

4.Mahmoodpoor A, Golzari SE, Hamidi M, Hamidi M, Parish M, Soleimanpour H, Mirinezhad M. Comparison of Three Methods for Laryngeal Mask Airway Insertion in Adults: Standard, Lateral and Rotational J Clin Anal Med 2013 (In Press)

5.Aghamohammadi D, Eydi M, Hosseinzadeh H, Rahimi MA, Golzari SE. Assessment of Mini-dose Succinylcholine Effect on Facilitating Laryngeal Mask Airway Insertion. Journal of Cardiovascular and Thoracic Research. 2013;5(1),17-21. 
6.Eydi M, Kolahdouzan K, Golzari SE. Effect of Intravenous Hydrocortisone on Preventing Postoperative Sore Throat Followed by Laryngeal Mask Airway Use in patients Undergoing Urogenital Surgeries. Journal of Cardiovascular and Thoracic Research. 2013;5(1),29-33.

7.Peirovifar A, Eydi M, Mirinejhad MM, Mahmoodpoor A, Mohammadi A, Golzari SE. Comparison of postoperative complication between Laryngeal Mask Airway and endotracheal tube during low-flow anesthesia with controlled ventilation. Pak J Med Sci 2013;29(2):601-605.

8. Hosseinzadeh H, Golzari SE, Torabi E, Dehdilani M. Hemodynamic Changes following Anesthesia Induction and LMA Insertion with Propofol, Etomidate, and Propofol + Etomidate. Journal of Cardiovascular and Thoracic Research, 2013, 5(3), 109-112

9.Panahi JR, Mahmoodpoor A, Golzari SE, Soleimanpour H. Baby cuff as a reason for laryngeal mask airway cuff malfunction during airway management for anesthesia. Saudi Journal of Anesthesia. 2014 (In Press)

10.Goudsouzian NG, Denman W, Cleveland R, Shorten G.(1992). Radiologic localization of the laryngeal mask airway in children. Anesthesiology, 77, 1085-9.

11.Gursoy F, Algren JT, Skjonsby BS.(1996). Positive pressure ventilation with the laryngeal mask airway in children. Anesth Analg, 82, 33-8.

12.Nunez J, Hughs J, Wereham K, Asa ,T.(1998). Timing of removal of the Laryngeal mask airway, Anaesthesia ,53,12630.

13.Kiching AJ, Walpole AR, Blogg CE.(1996). Removal of the Laryngeal mask airway in children: Anaesthesized compared with awake. B.J Anaesth ,76,874-6.

14.Ferarri LR, Goudsouzian NG.(1995). The use of the laryngeal mask airway in children with bronchopulmonary dysplasia. Anesth Analg,81,310-13.

15.Laffon M. Plaud B, Dubousset AM, Berhaj R, Ecoffe JC.(1994). Removal of Laryngeal mask airway: airway complication in children. Anesthetized versus awake. Paedit Anaesth,4,35-7.

16.Bagshaw 0.(2002). The size of laryngeal mask airway in paediatric practice. Paed Anaesth, 12, 420-3.

17.Mason DG, Bingham RM.(1990.)The laryngeal mask airway in children. Anaesthesia,45, 760-3

18.O' Brien B, Harmon D, Duggan M, Flynn N.(2002). Laryngeal mask cuff inflation at removal does not affect early postoperative laryngopharyngeal morbidity. Can J Anaesth,49(8),871-3.

19. Howard G,Butler PJ,Baxter P.(1997). The Laryngeal Mask Airway: A Comparison Between Two Insertion Techniques.Anesth Anal 